CASE REPORT

\title{
Axis Metastasis, Atlantoaxial Dislocation and Cervical Syringomy- elia: A Case Report
}

\author{
Ismail Latifaci, $M D^{1 *}$, Selcuk Gozcu, MD² and Ahmet Celal Iplikcioglu' \\ ${ }^{1}$ Department of Neurosurgery, Bahcelievler Government Hospital, Turkey \\ ${ }^{2}$ Department of Neurosurgery, BHT CLINIC Istanbul Tema Hospital, Turkey
}

*Corresponding author: Ismail Latifaci, MD, Department of Neurosurgery, Bahcelievler Government Hospital, Istanbul, Turkey, Tel: +90-212-496-7070, Fax: +90-212-496-70-96

\begin{abstract}
Syringomyelia associated with atlantoaxial dislocation is usually described in patients with complex craniovertebral junction anomaly. However, atlantoaxial dislocation without craniovertebral junction bony anomaly very rarely causes syringomyelia. In this report, we describe a case of syringomyelia associated with atlantoaxial dislocation secondary to metastatic tumour of the axis vertebra.
\end{abstract}

\section{Keywords}

Syringomyelia, Atlantoaxial dislocation, Craniovertebral junction, Tumour of the axis

\section{Introduction}

Syringomyelia is characterized by the presence of a fluid filled cystic cavity within the spinal cord. Cervical syringomyelia is usually associated with Chiari malformations, tumours or as a consequence of trauma [1,2]. Craniovertebral junction (CVJ) bony anomalies, including atlantoaxial vertical dislocation and basilar invagination with or without tonsillar herniation, can also cause cervical syringomyelia $[3,4]$. Simple or horizontal atlantoaxial dislocation-associated syringomyelia is very rarely reported [5-7]. We describe a very rare case of syringomyelia caused by atlantoaxial dislocation associated with metastatic tumour of the axis.

\section{Case Report}

A 65-year-old woman was admitted with a 6-month history of neck pain complaint of weakness in all extremities. Neurological examination revealed quadriparesia with brisk deep tendon reflexes in all four limbs.
Pin prick sensation was reduced bilaterally below the $\mathrm{C} 5$ level; neck movement was reduced because of pain. The bilateral Babinski sign was positive. Plain skull and cervical X-rays showed an atlantoaxial dislocation. Magnetic resonance (MR) examination revealed an atlantoaxial dislocation with a tumoral mass involving the corpus of axis, with cervical syringomyelia (Figure 1). Computed tomography (CT) disclosed the destruction of the corpus of axis (Figure 2). In the first operation, $\mathrm{C} 1$ laminectomy and occipito-cervical fusion using C2 laminar and C3C4 lateral mass screwing was performed. Following C1 laminectomy, dural pulsation was observed. Two days after the first operation, partial excision of the tumour mass was performed, and the bone defect was filled with acrylic to stabilize the segment. Histopathological examination resulted in a diagnosis of adenocarcinoma metastasis. Postoperative symptoms improved and control MR imaging showed that the syrinx was reduced (Figure 3). The patient was transferred to the oncology unit and died 6 months following surgery because of extensive metastasis of lung carcinoma.

\section{Discussion}

The most common cause of atlantoaxial dislocation is trauma. Rheumatoid arthritis, congenital CVJ anomalies, infection and tumours of the CVJ are other causes. Tumours affecting the osseous and ligamentous structures of CVJ are rare, and can be classified as primary, secondary or miscellaneous [8]. Primary tumours are bone tumours, such as osteoma, osteochondroma and chordoma. Metastatic tumours of the CVJ are very rare. Piper and Menezes reported 14 patients treated

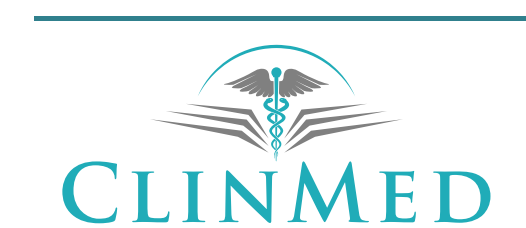

INTERNATIONAL LIBRARY
Citation: Latifaci I, Gozcu S, Iplikcioglu AC (2020) Axis Metastasis, Atlantoaxial Dislocation and Cervical Syringomyelia: A Case Report. Neurosurg Cases Rev 3:038. doi.org/10.23937/2643-4474/1710038 Accepted: June 17, 2020; Published: June 19, 2020

Copyright: (c) 2020 Latifaci I, et al. This is an open-access article distributed under the terms of the Creative Commons Attribution License, which permits unrestricted use, distribution, and reproduction in any medium, provided the original author and source are credited. 


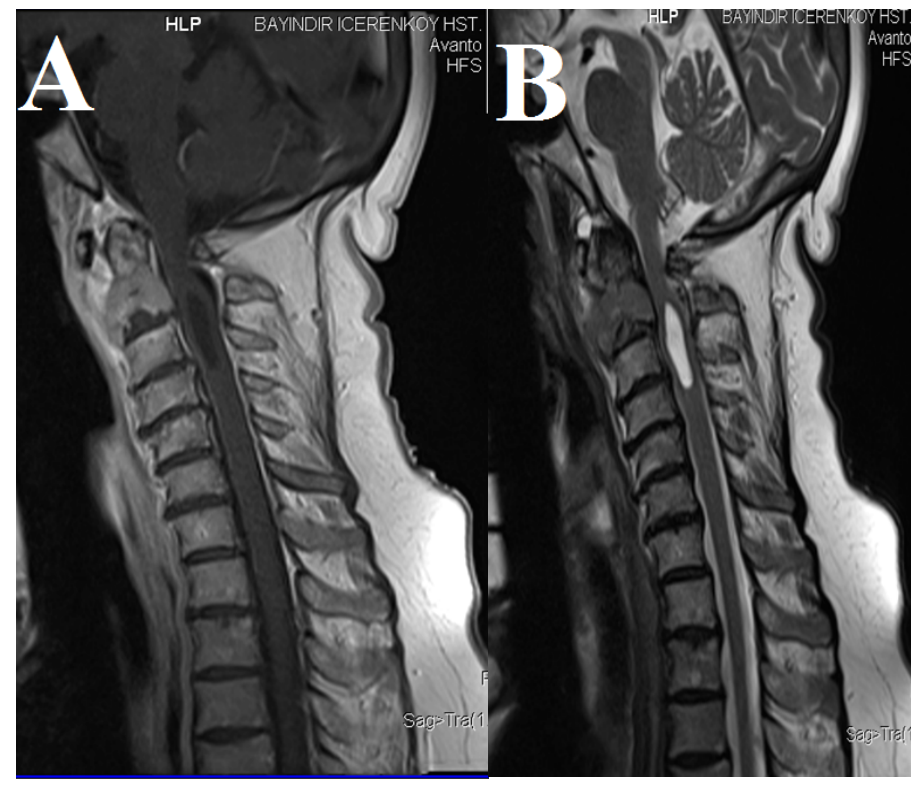

Figure 1: Pre-operative T1 Weighted. A) T2 Weighted; B) MRI Examination of cervical spine show metastatic tumor of axis atlantoaxial dislocation and cervical syringomyelia at C2-3 level. Posterior arc of C1 vertebra compress the spinal cord and posterior subarachnoid space.

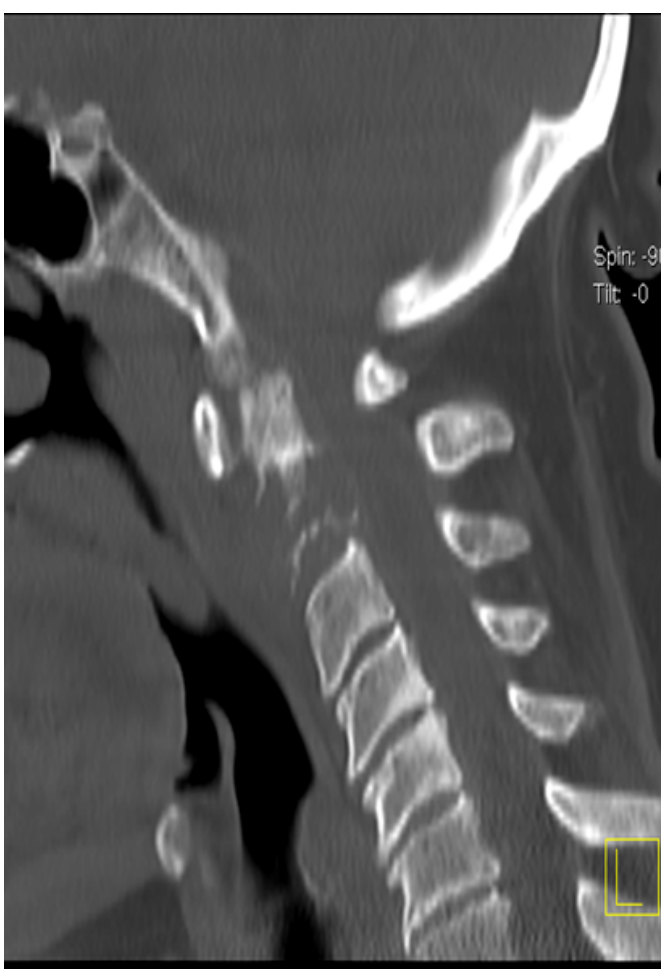

Figure 2: Computerized Tomography of cervical spine showing osteolytic lesion of axis body and atlantoaxial dislocatio. Increase of atlanto dental space is also seen.

for tumours of the axis, and only two were metastatic [8]. Shin, et al. reported 51 cases of CVJ tumours, and only three were found to be metastatic [9]. However, tumours producing bone destruction commonly cause instability of the cervical spine. In the series reported by Piper and Menezes, eight of 14 patients presented with instability of the cervical spine [8], which was also seen in our patient.

According to Goel, et al., cervical syringomyelia is usually associated with Chiari malformation with or without basilar invagination [3]. In such cases, the abnormal position of atlantoaxial joint as a result of congenital bone anomaly causes slippage of the atlas over the axis and invagination of odontoid process [10]. That type of atlantoaxial dislocation is described as a 'vertical' dislocation. However, simple or horizontal atlantoaxial dislocations very rarely cause syringomyelia, and few cases have been reported [5-7].

Goel, et al. reported three infants with atlantoaxial dislocation-associated syringomyelia treated with atlantoaxial fixation [5]. In a case reported by Mizutani, et al., loosening of multistrand cables following C1-C2 Brookstype fusion resulted in syringomyelia [6]. Yoong, et al. also reported a case of atlantoaxial dislocation-associated syringomyelia in a patient with rheumatoid arthritis [7].

Although the pathogenesis of syringomyelia is unclear, impairment of subarachnoid cerebrospinal fluid (CSF) flow is involved in cases of atlantoaxial dislocation with syringomyelia [4]. CSF flow obstruction at the dislocation level is similar to that of Chiari malformation, which prevents the return of spinal CSF and increases perivascular flow from the subarachnoid space, leading to the syrinx formation [2]. In horizontal atlantoaxial dislocation, as in our patient, dorsal compression by the posterior arch of the atlas is more prominent. In the case reported by Mizutani, loose cables of a Brooks-type fusion compressed subarachnoid pathways [6]. Decrease in the blood supply of the spinal cord resulting from atlantoaxial dislocation, tumours, or rheumatoid vascular compression can also cause ischemic necrosis and cavity formation in the spinal cord. Regardless of the pathology, treatment of atlantoaxial dislocation associated with syringomyelia includes atlantoaxial stabilization and restoration of the obstructed subarachnoid space. 

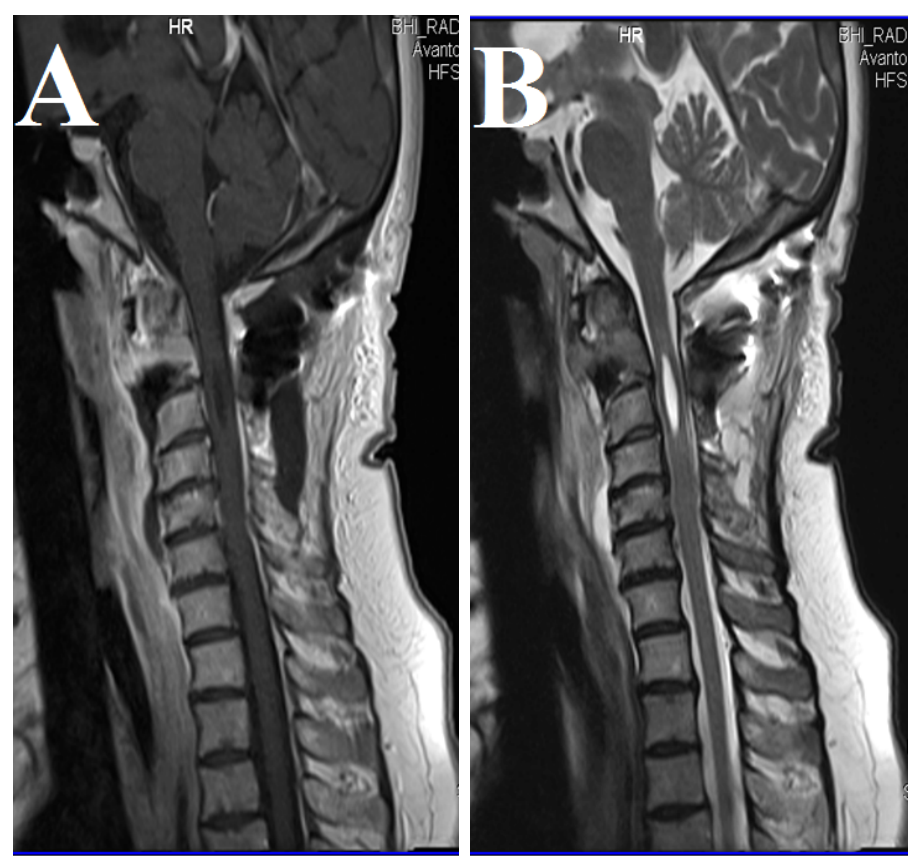

Figure 3: Pre-operative T1 Weighted. A) T2 Weighted; B) MRI Examination of cervical spine reveal decompretion of spinal cord and subarachnoid space at $\mathrm{C} 1$ level and decrease of syringomiyelic cavity.

Clinical and radiological improvement usually occurs soon after surgery. However, we chose occipitocervical stabilization and C1 laminectomy for decompression in our patient because of the malignant nature of the disease and the irreductable atlantoaxial dislocation.

\section{Conclusion}

Metastatic axis vertebrae tumours rarely cause atlantoaxial dislocation and syringomyelia. Occipitocervical stabilization and decompression of subarachnoid space are essential in the cases with irreductible atlantoaxial dislocation.

\section{References}

1. Klekamp J, Batzdorf U, Samii M, HW Bothe (1996) The surgical treatment of Chiari I malformation. Acta Neurochir (Wien) 138: 788-801.

2. Klekamp J, laconetta G, Batzdorf U, Samii M (2002) Syringomyelia associated with foramen magnum arachnoiditis. J Neurosurg 97: 317-322.

3. Goel A, Sharma $P(2005)$ Craniovertebral junction realignment for the treatment of basilar invagination with syringomyelia: Preliminary report of 12 cases. Neurol Med Chir (Tokyo) 45: 512-517.
4. Wang Z, Wang X, Jian F, Zhang C, Wu H, et al. (2017) The changes of syrinx volume after posterior reduction and fixation of basilar invagination and atlantoaxial dislocation with syringomyelia. Eur Spine J 26: 1019-1027.

5. Goel A, Muzumdar D, Dange N (2007) Syringomyelia in infants secondary to mobile congenital atlantoaxial dislocation. Pediatr Neurosurg 43: 15-18.

6. Mizutani J, Tsuboucim S, Fukuoka M, Otsuka T, Matsui N (2002) Syringomyelia caused by loosening of multistrand cables following C1-2 Brooks-type fusion in the rheumatoid cervical spine. Case report. J Neurosurg 97: 366-368.

7. Yoong JK, Fong KY, Tang KK, Tan RK, Thumboo J (2007) Rheumatoid-atlantoaxial disease associated syringomyelia: A causal link? Ann Acad Med Singapore 36: 150-151.

8. Piper JG, Menezes AH (1996) Management strategies for tumors of the axis vertebra. J Neurosurg 84: 543-551.

9. Shin H, Barrenechea IJ, Lesser J, Sen C, Perin NI (2006) Occipitocervical fusion after resection of craniovertebral junction tumors. J Neurosurg Spine 4: 137-144.

10. Goel A (2015) Is atlantoaxial instability the cause of Chiari malformation? Outcome analysis of 65patients treated by atlantoaxial fixation? J Neurosurg Spine 22: 116-127. 